sala preta

ppgac

\title{
Iluminação cênica: possibilidades de um sujeito em cena
}

Stage lighting: possibilities of a subject on stage

Felipe Braccialli

Felipe Braccialli

Mestrando em práticas e processos em artes na Universidade Federal de Uberlândia

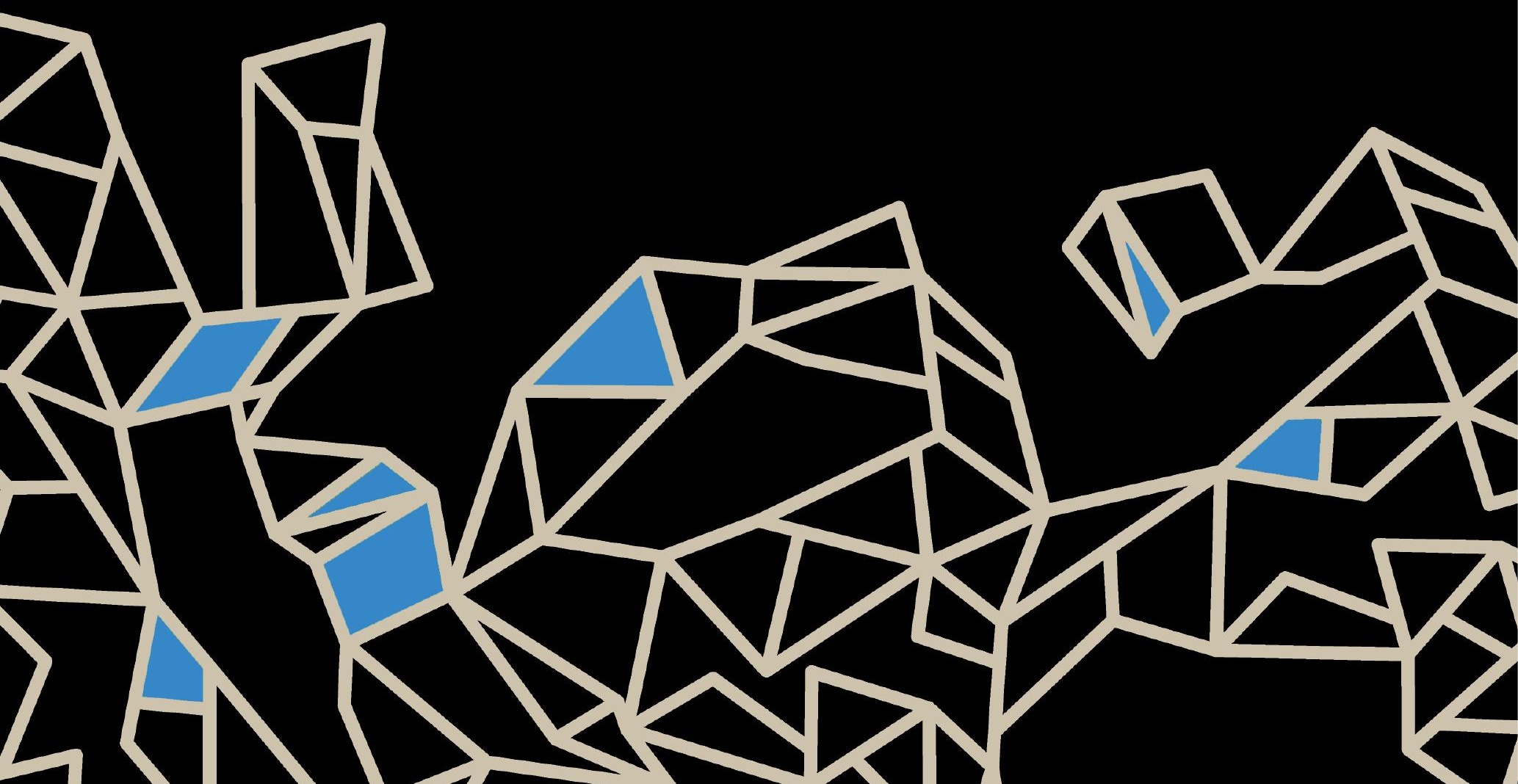




\section{Resumo}

Este artigo faz uma reflexão sobre a importância e as capacidades que a iluminação cênica tem no desenvolvimento da concepção de um espetáculo. Pensar em iluminação cênica é abrir um enorme leque de possibilidades para pesquisa e criação. $O$ artigo aborda principalmente trabalhos nos quais esse recurso cênico é usado em cenas cômicas. Com base na experimentação prática realizada durante a pesquisa com alunos do Curso de Teatro da Universidade Federal de Uberlândia (MG), foi possível refletir sobre as capacidades que a iluminação tem ao se potencializar como sujeito de uma situação cômica, a partir da relação criada entre o(a) ator(atriz) e a luminotécnica.

Palavras-chave: Iluminação cênica, Comicidade, Personagem.

\section{Abstract}

This article proposes a reflection about the importance and the creative possibilities that stage lighting adds to theatrical creative processes. To think about stage lighting is to open a vast range of possibilities for research and creation. The article approaches mainly the experiences in which the lightning resources are used in comic scenes. Based on an empirical study performed along with students from the Drama Course at the Universidade Federal de Uberlândia (MG, Brazil), it was possible to reflect on the capabilities that the lighting has when leveraging itself as a subject of a comic situation, through the relation created between the actor/actress and the lighting technique.

Keywords: Stage lighting, Comedy, Character.

A função primária da luz em cena nada mais é do que a mesma do cotidiano: possibilitar que os corpos e materiais dispostos no espaço sejam percebidos por seus observadores. A reflexão dos feixes de luz em um corpo opaco em direção ao olho é o que nos permite ver, constituindo um esquema razoavelmente eficiente acerca do fenômeno da visão. Ainda assim, é compreensível que existam diversas outras formas de se perceber esse mesmo corpo pela visão, dependendo de diferentes características atribuíveis ao feixe de luz.

Quando não é realizado um trabalho apropriado das qualidades cromáticas dos elementos das cenas, como o cenário e os figurinos, a iluminação 
pode prejudicar o produto final, desviar as cores propostas para tons inapropriados que não sugiram determinadas nuances psicológicas, simbólicas ou expressivas (PEREZ, 2007).

A função da iluminação no teatro é proporcionar percepção visual da cena para o espectador, ou seja: o modo como uma cena é iluminada (em intensidade, diversidade, direções focais e escolhas cromáticas) influi diretamente sobre a maneira como é percebida, podendo incorporar-se aos elementos da narrativa e das tensões dramáticas e simbólicas apresentadas.

Dessa forma, a luminotécnica poderia ser definida como a maneira que uma cena é iluminada, independentemente da ação de uma força criativa intencional (o sol, a sombra de uma árvore, a luz de uma sala ou uma geral fixa, posta apenas para viabilizar a percepção visual). A iluminação cênica seria assim entendida como o esforço criativo consciente de empregar recursos específicos da luminotécnica de modo a participar da cena, contribuindo para os sentidos que busca produzir e colaborando com a concepção estética.

Com isso, a concepção da iluminação cênica não deveria ser um elemento pensado separadamente da cena; pelo contrário, os efeitos luminotécnicos, quando construídos em conjunto com a cena (cenário, figurino, maquiagem e qualquer outro elemento que venha a compor o espetáculo), favorecem a composição de sentidos na obra de arte.

Para Camargo (2006), corpo e luz não se separam; necessitamos da luz para enxergar as coisas e precisamos das coisas para perceber a luz. Assim, a percepção do mundo físico depende da interação entre luz e matéria. Transportando essa coexistência para a relação que se faz, no teatro, entre luz e cena, questiona-se: a luz poderia participar do espetáculo sendo algo além de um recurso de viabilização da visão? Um efeito de luz seria capaz de representar? Ou, ao menos, de ser percebido pelo espectador como índice de uma presença? De provocar a percepção, ou mesmo de representar um sujeito em cena? Indo mais longe: um efeito de luz seria capaz de desempenhar um personagem ou tipo, em uma cena cômica?

A pesquisa desenvolvida por mim, em nível de mestrado, parte da indagação sobre as possibilidades e modos de se atribuir a efeitos de iluminação cênica a percepção de uma subjetividade, acompanhada pela reflexão sobre as formas de manipulação dos recursos de luminotécnica que podem auxiliar 
e potencializar tal percepção. Busca-se, assim, identificar e analisar os efeitos de iluminação cênica que são usados em algumas cenas cômicas como propositores e participantes diretos das suas ações.

O trabalho iniciou-se com o levantamento de vídeos, via internet, relacionados à iluminação e comicidade. Foram encontrados diversos vídeos nos quais pessoas usavam luzes para brincar com seus animais de estimação, estimulando-os a perseguir os pontos luminosos direcionados nas paredes ou no chão. Para o animal, a luz refletida é algo interessante e novo que faz parte do mundo material à sua volta. O problema é que a luz não pode ser agarrada, e os animais desconhecem a maneira como é produzida e controlada. Ainda assim, pode ser interessante perceber que o animal entende a luz como objeto independente da lanterna. Com essa percepção do ponto luminoso como objeto, é possível começar a construir situações nas quais a iluminação ganha outras potências, em cena.

A confusão que se faz na percepção do efeito luminoso, entre sua evidência visual e o fato de ser inapreensível, já é em si sugestiva quanto à variedade de situações de engano e desencontro que pode provocar. Nesse sentido, evidencia-se um potencial cômico inequívoco.

Também foram encontrados vídeos que apresentavam a interferência do foco luminoso na criação de comicidade, em desenhos animados. Um deles foi a abertura do desenho Pernalonga e Patolino, o qual era transmitido no canal de televisão CartoonNetwork (BUGS..., 2014). Outro desenho animado encontrado tinha como personagem central o Pica-Pau, no começo do episódio "O passarinho do relógio" (O RELÓGIO..., 2015). Em ambas as cenas, percebe-se a interferência de recursos de iluminação representados na forma do desenho animado, atuando como objeto indutor de comicidade. A iluminação cênica funciona como recurso acessório ao jogo das personagens.

Se, no primeiro vídeo, a incapacidade do personagem Patolino de ganhar aplausos é revelada por um equipamento técnico acionado diretamente por Pernalonga, no segundo, a não revelação do sujeito responsável pelos efeitos de abertura da cortina e da intermitência da luz atua como sugestão de uma autonomia e até mesmo de intencionalidade na atuação desses elementos, o que chega a propor que tais efeitos, os quais podem ser involuntários e inconscientes, são executados por um sujeito, ou que o próprio efeito 
de iluminação constitui um sujeito, em seu próprio direito. Assim, iniciamos nossas considerações acerca do uso da iluminação para produzir personagens cômicos.

Continuando a busca por vídeos na internet, imagina-se que $\mathrm{o}$ assunto talvez não tenha sido explorado o suficiente, pela dificuldade de encontrar trabalhos relacionados. Procurando principalmente peças e gags que envolvem a iluminação como fator principal para a produção de comicidade, um único vídeo foi encontrado: uma gag do palhaço italiano David Larible.

Nessa gag, o foco de luz cria uma relação com o palhaço inserida no jogo de comicidade que se instaura em cena. É possível atribuir qualidades de comportamento as quais sugerem que o efeito luminoso possui autonomia em suas decisões, dando a impressão da manifestação de uma subjetividade autônoma. Um jogo de ações e reações, de humores e imprevisibilidades se instaura entre os dois personagens, transmitindo a sensação do foco de luz ser vivo e ter personalidade, chegando até a se comunicar com o palhaço. Ele participa da cena de forma que escapa à função primordial da iluminação cênica, representando sujeito da ação cênica para construção da comicidade da gag, pois, sem ela, o jogo e a relação de dupla não aconteceria. $O$ foco de luz não ilumina, não amplia as tensões ou orienta a leitura da cena. $O$ foco é um ator da cena cômica, reagindo, mostrando intenções e estados de humor.

A partir dessa análise, surgiu o interesse de experimentação prática das possibilidades de a iluminação cênica se envolver em cenas cômicas. Optou-se por trabalhar com a linguagem do palhaço pela lógica distorcida da realidade provocada pela máscara. $O$ palhaço consegue criar uma lógica diferenciada de trabalho, na qual qualquer elemento pode ganhar potência cênica de parte de uma dupla cômica.

Para a realização da pesquisa com base na prática em estúdio, foram convidados dois alunos do Curso de Teatro da Universidade Federal de Uberlândia (UFU): Eluhara Resende e Guilherme Conrado, com 22 anos de idade e experiência em trabalho como palhaço.

Foi pedido que os participantes da pesquisa trouxessem fotos, vídeos e músicas que quisessem usar durante o processo, e que, de preferência, tivessem relação com luz. Ficaram também livres para trazer qualquer tipo de 
material que os remetesse à pesquisa e que de alguma maneira pudesse ser aproveitado.

Nesse levantamento de material dos atores, mais uma cena foi encontrada em que existia uma relação direta entre a iluminação e a comicidade. O ator Guilherme trouxe um vídeo de uma cena do espetáculo Varekai ${ }^{1}$, do Cirque du Soleil. O ator e criador da cena, Cláudio Carneiro, constrói a dupla cômica do trabalho através de um efeito de iluminação cênica, mas direcionado ao operador do canhão seguidor da cena. $O$ ator entra em cena pronto para cantar uma música para o público, todo confiante em seu trabalho. Aos poucos, a iluminação começa a se movimentar no espaço, deixando-o no escuro. A todo momento, o ator tenta retornar ao foco de luz, mas sem sucesso. A cena vai se desenvolvendo e a iluminação cria situações de dificuldade para o ator, provocando o riso nos espectadores (CARNEIRO, 2015).

Com base nessa cena, foi solicitado a cada ator que trouxesse uma música que conseguisse cantar por inteiro com a ideia de reproduzi-la. Duas ideias de cenas para experimentação resultaram dessas músicas: a primeira cena, partindo da música Na vida Anterior, de João Guarizo (GUARIZO, 2014), proposta pela atriz Eluhara, foi nomeada de "Sorvete"; a segunda, proposta pelo ator Guilherme, partindo da música "Como nossos pais", de Belchior, interpretada por Elis Regina (BELCHIOR, 2014); finalmente, a música da cena do espetáculo Varekai, intitulada "Não olha agora: tem um palhaço atrás de você".

Na cena "Sorvete", a música escolhida apresenta uma poesia cômica. A letra beira o absurdo e traz a todo o momento elementos inesperados para o espectador. Aproveitando essa comicidade da música, deixamos Eluhara cantar com o estímulo de sempre estar em destaque na cena, enquanto GuiIherme dança ao lado dela, de modo a produzir o jogo da cena.

A cena é: a palhaça entra como uma cantora renomada para fazer seu show. Com a ideia de deixar sua apresentação mais rebuscada, convida outro palhaço para realizar uma coreografia preparada para a primeira música do show. A música começa e a cantora está mais bem iluminada que o bailarino, com mais intensidade de luz, diversos refletores direcionados para ela,

1 Espetáculo do Cirque du Soleil, estreado em 2002, dirigido por Dominic Champagne, com iluminação de Nol Van Genuchten. 
enquanto o outro está sendo iluminado somente o suficiente para ser visto. Com o passar da cena, o interesse da iluminação começa a se tornar outro, diminuindo a quantidade de luz voltada para a cantora e aumentando a do bailarino, dando, assim, maior destaque a ele. Esse interesse da iluminação seria traduzido também como o interesse do público na cena. Dessa forma, existia a vontade da palhaça de sempre ter o máximo de luz possível em sua direção.

A partir desse conflito, em que a palhaça quer ser o centro da atenção, chegando até a menosprezar o bailarino, enquanto a iluminação/plateia se diverte mais com a performance do outro palhaço, começa o jogo cômico da cena. A palhaça tenta ser o centro de atenção no palco, mas a iluminação vai mudando, dando destaque para o bailarino, deixando a cantora quase no escuro. Irritada e não aceitando a situação, corre para o lugar onde o bailarino se encontra, empurrando-o à força para sair. Com isso, a cena se desenvolve até o momento em que a palhaça expulsa o bailarino do palco e termina a música, brava. Ela recebe os aplausos e fica no escuro. Alguns segundos se passam, o bailarino entra e todos os refletores o iluminam para que agradeça.

Já na outra cena, de "Não olha agora: Tem um palhaço atrás de você", o trabalho parte da releitura do vídeo trazido pelo ator Guilherme do Cirque $d u$ Soleil. Como já citado, o jogo de cena é o ator tentar se manter na luz para fazer sua apresentação enquanto o cone de luz foge a todo o momento dele, criando as mais diversas situações. Pensando nessa relação, foram experimentadas diferentes formas de realizar a cena.

O trabalho foi desenvolvido na sala de encenação que compõe o Laboratório de Interpretação e Encenação (LIE) do Curso de Teatro da Universidade Federal de Uberlândia, pelo período de seis meses. A Sala de Encenação possui 14,70 metros de largura por 14,92 metros de profundidade, com um pé direito de 7,61 metros, apresentando, assim, uma altura de vara de 6,50 metros. As paredes são pintadas de preto. As varas de iluminação posicionam-se apenas sobre as varandas que contornam a sala, dificultando a exploração de uma maior variedade de angulações e direcionamento de refletores. Além da dificuldade estrutural, o laboratório carece de equipamentos. Foram disponibilizados para a pesquisa uma mesa digital Tec Port Stage 24 canais, 23 canais de dimmer, que aguentam 4000W cada, 16 PAR 64 \#5 (1000w), 7 PAR 64 \#2 (1000w), 8 PAR 56 \#5 (300w), 4 PAR 56 \#2 (300w) 3 PAR 56 \#1 (300w) 
6 PAR 36 (300w), 4 Elipsoidal Telem (1000w) com faca, íris, porta gelatina e porta gobo, 4 Fresnel Telem (500w), 3 PC Telem (1000w), 4 PC (500w), 6 Set Light de 1000w e 8 de 500w.

Para as experimentações, foram consideradas as possibilidades e dificuldades existentes no espaço de criação, tais como a utilização do espaço arquitetônico como estímulo para o desenvolvimento da cena e a carência de equipamentos de iluminação cênica. Durante o processo, outros objetos encontrados na sala começaram a se integrar na apresentação conforme necessário.

No decorrer do processo de criação da cena, percebeu-se dificuldade na percepção da iluminação cênica pelo ator, o qual não sabia se posicionar corretamente na luz. Um trabalho foi realizado para desenvolver sua percepção, pois, com o olhar mais sensível do intérprete para os efeitos luminosos, a cena ganha uma nova potência e aumenta as possibilidades de estímulos para o processo criativo.

Ao pensar na relação entre luz e cena, vemos que não podemos dissociar uma da outra, porque são coexistentes. A luz não pode ser considerada como um corpo estranho, ao qual o ator deve se ajustar, uma vez que cena e luz são fenômenos simultâneos; um se revela por meio do outro, há troca de experiência, fluxo de vibração e impermanência (CAMARGO, 2006). A relação entre o ator e a iluminação tem que ser natural, de sorte que um deve complementar o movimento do outro.

Por isso, é essencial que os atores tenham essa percepção desenvolvida: só assim a troca de experiência entre os dois acontece. Como já frisado, para pensar sobre a cena, é necessário pensar sobre a luz. A coexistência luz e cena tem que ser aceita e construída cuidadosamente, a fim de que o espetáculo não se torne fragmentado de sentidos.

O trabalho de percepção da iluminação teve continuidade e simultaneamente se iniciou a criação da cena, com ajuda de Thabatta Ferreira, que se juntou ao grupo, dando apoio de direção. Com o tempo, surgiu a necessidade de mais uma pessoa no processo para ficar responsável pela operação da mesa de luz, e foi chamado mais um aluno do Curso de Teatro, Adriel Parreira, para participar do trabalho.

Foram definidos os equipamentos que seriam usados para essa cena: quatro projetores elipsoidais e um projetor PC. A escolha se deu pela neces- 
sidade de equipamentos que permitissem uma luz marcada e regulável para o jogo acontecer, e também pelo contraste de luz, de claro e escuro, estando presente só no cone de luz do projetor; fora dele, o público não conseguiria ver o que se passa. O foco marcado foi escolhido para que fosse possível perceber a movimentação da iluminação no corpo do ator.

O processo pedia equipamentos os quais o curso não tinha disponíveis, como um canhão de luz seguidor. A cena, além de ter movimentação de luz pela mudança de projetores ligados, pedia igualmente um equipamento que possibilitasse movimentar o cone de luz manualmente. Como solução, foi empregado um projetor PC devido à leveza do equipamento, facilitando sua movimentação para a cena, com filtro de luz. Esse filtro de luz foi confeccionado pelos participantes do trabalho em papel paraná ${ }^{2}$. Foi utilizado pela necessidade de um cone de luz menor que o equipamento possibilitava. Mesmo com essa solução, não foi o ideal para a cena, pois o projetor PC, apesar de ter uma luz marcada, ainda tem escape de luminosidade para fora do foco.

Tem início a criação da cena, primeiramente com estrutura simples, tanto de operação de luz como de movimentação do ator em cena. A iluminação cênica cria o jogo de direcionar o ator pelo espaço, indicando onde ele deve ir ou ficar. Aos poucos, começa a enganá-lo, para que ficasse perdido no espaço; dessa forma, sempre que o ator alcançava o cone de luz, este era posicionado para o outro lado da cena. Iniciou-se, assim, a relação de dupla entre ator e iluminação cênica.

Surge a necessidade de fechar o desenho da cena, criando marcações para cada momento da música e definindo o tempo para as coisas acontecerem. Ao criar essa estrutura de cena fechada, desenhando o espaço que o ator e a iluminação seguiriam na apresentação, o ator perdia o frescor do jogo que existia quando não sabia onde o cone de luz estaria. Com a ciência de onde a iluminação estaria, adiantava-se para o espaço e perdia o tempo de resposta. A cena ganha potência cômica pela reação do ator com os fatos que se sucedem; para isso, é essencial a veracidade das respostas, tentando ao máximo impedir que seja uma reação cristalizada.

2 A escolha do papel paraná se deu por sua capacidade de aguentar altas temperaturas sem degradação. 
Em seguida, com a estrutura da cena basicamente pronta, foi inserida a máscara do palhaço. O jogo ganha, por conseguinte, outra potência, pois outro universo é instaurado em cena. Com o nariz de palhaço, as movimentações que estimulavam a comicidade começam a ter sentido, fortalecendo, assim, a dupla cômica que se instaura em cena. A relação entre o palhaço e a iluminação desenvolve uma potência de personagem para o cone de luz, deixando de ser um elemento técnico da cena para se transformar em um ser lúdico do espetáculo.

Tal situação é comum em desenhos animados, que transformam animais e objetos em parte da dupla cômica da cena. É o caso de Salsicha e Scooby Doo: o cachorro beira a humanidade, agindo como uma pessoa, mas não perdendo sua natureza animalesca, constituindo a dupla cômica de Salsicha. No desenho animado, a facilidade de criar uma dupla cômica de seres inanimados ou irracionais é maior, pois a imaginação pode voar livre e não tem limites de possibilidades.

Também poderiam ser citados aqui alguns exemplos de duplas cômicas em que o intérprete joga com algo inanimado, como é o caso de Mr. Bean, que trabalha principalmente criando sua dupla com objetos. Harold Lloyd, Roberto Gómez Bolaños e Charles Chaplin são ainda alguns exemplos que podem ser citados de comediantes que trazem à cena objetos como seu duo.

O palhaço, a todo o momento, está jogando com alguém ou algo, seja um parceiro de cena, seja público, objeto, luz ou ele mesmo, de sorte que em nenhum momento fica sozinho. Nesse sentido, é por essa capacidade inerente que se decidiu trabalhar com o palhaço.

Gomes (2012) propõe que o palhaço em cena não se encontra sozinho, porque se identifica com o todo, sua plateia e o inconsciente coletivo. Nos dias atuais, quando considerado o aspecto artístico, observa-se que o palhaço se multiplicou e trouxe um parceiro, o outro de si mesmo, com a ressalva de que não se trata de outro igual, mas um opositor que o complementa.

Esse outro, que nem sempre é outro ator, é o que completa a todo o momento o palhaço, é sua dupla cômica, seu parceiro de jogo: sem ele, a cena não se desenvolve, porque sozinho não existe conflito. Em dupla, algo novo sempre aparece e se transforma, um estímulo leva a outro e se torna uma constante. No caso da pesquisa, a luz é o que completa a dupla cômica, pois a todo o momento estimula as mudanças, os conflitos e o jogo da cena. 
Com essa dupla cômica e o jogo da cena instaurado, conseguimos trazer novas qualidades para o trabalho. No momento em que se "humaniza" o cone de luz como personagem é que o jogo se desenvolve, a comicidade da cena se potencializa e promove o andamento do processo criativo.

\section{Conclusão}

Ao trabalhar na construção de um espetáculo, é importante pensar nos diferentes estímulos visuais e sonoros com os quais se pretende lidar, com atenção especial para as tecnologias da cena necessárias para se alcançar os efeitos desejados. Esse cuidado, o qual pressupõe diretamente o trabalho com a iluminação cênica, quando ocorre concomitantemente ao processo de criação da cena, permite aos artistas de teatro um melhor aproveitamento das suas possibilidades expressivas. Não apenas o trabalho dos atores e do diretor, mas também o do iluminador são elementos essenciais para a criação do espetáculo.

A iluminação, enquanto objeto de proposição de estímulos para a criação de cena, tem grande potência para o desenvolvimento da peça e para que a montagem seja conectada entre todos os seus elementos. Criar a possibilidade dos atores improvisarem e entenderem a iluminação cênica pode contribuir para o desenvolvimento das personagens - principalmente em aspectos de atmosfera, tempo e emoção (MOURA, 2014) -, além de propiciar que novos universos se insiram na criação, ampliando o leque de possibilidades para o espetáculo.

Também é possível perceber que a iluminação cênica, além de permitir a percepção visual e desenvolver a estética do trabalho, consegue ganhar a potência de se envolver com outras funções, como a de sujeito de diferentes ações e situações. Insere-se no trabalho como personagem de cena pelo envolvimento e relação criada pelo ator. Assim, possibilita a relação de identificação de alguns efeitos de iluminação cênica com a função da personagem, pois esse jogo instaura a possibilidade de o público perceber a luz dessa forma. A cena se cria a partir do jogo desenvolvido entre ator e iluminação, que, como dupla, constroem a comicidade da cena.

A luz consegue entrar no jogo do palhaço e, consequentemente, torna-se objeto passível de participar de jogos de relação e manipulação (podendo fazer 
uma ligação com o Teatro de Animação, no qual a manipulação dos objetos instaura a percepção da personagem em cena). Ganha textura, peso, tamanho, torna-se palpável pelo palhaço. Ao mesmo tempo, a relação entre iluminação e ator permite que o efeito luminoso seja percebido como elemento autônomo e presente em cena, de modo a sugerir uma personagem feita de luz (luz-personagem), capaz de apresentar qualidades de ator. Insere-se no jogo do palhaço de maneira semelhante aos que se veem em desenhos animados: (supostamente) anda, fala, faz tudo que se possa imaginar e ainda desafia as leis da gravidade, saindo do mundo real e acessando o mundo da imaginação.

Com a manipulação da iluminação cênica, podemos construir diferentes formas de sugerir luzes-personagem. A luz pode ser uma extensão do corpo do operador de iluminação, que presentifica suas vontades, sentimentos e pessoalidades em cena, por meio da manipulação da fonte luminosa, sem dar vida à luz, mas se revelando por meio dela. Ou então construindo com o ator a presença viva do efeito de iluminação, em uma relação típica de duplas cômicas. $\mathrm{O}$ ator potencializa a proposta de fazer atuar a luz manipulada, dando a possibilidade de entendimento para o público de que ela tem personalidade, vontades e sentimentos; a luz-personagem completa o jogo instaurado.

A iluminação consegue desempenhar diversas funções em cena, desde iluminar o espaço, criar ambientes, ser cenário, transformar figurinos, até realizar a função de personagem. Ela opera em dinâmicas de percepção, desde as mais objetivas até as mais sutis. Ao conhecer todas as potencialidades que a iluminação tem a oferecer para a cena, é improvável não sentir-se impelido a explorar os meios pelos quais pode ser possível aproveitar suas possibilidades ao máximo, incorporando-a ao próprio processo de criação em cena, e envolvendo esse âmbito da criação cênica ao processo desde os estágios iniciais, com o auxílio de um profissional criador especializado na pesquisa da iluminação.

A pesquisa continuada do trabalho da iluminação cênica é fundamental para o maior entendimento das capacidades que oferece ao espetáculo teatral. As suas possibilidades criativas e expressivas, já ilimitadas, ampliam-se constantemente no ritmo das novas descobertas tecnológicas. Que funções a pesquisa em iluminação pode desempenhar em processos de criação de cenas? Que novas funções podem advir dos esforços de reflexão e da exploração dos materiais de luz? Como aprofundar o entendimento da inserção dos 
efeitos luminotécnicos em jogos de comicidade? São perguntas que alimentam a continuidade da pesquisa, uma vez que as novas chances aparecem enquanto essas palavras são escritas.

\section{Referências}

BUGS and Daffy: opening and closing. Disponível em: <http://www.youtube. com/watch?v=iJ0BxU8CiJw>. Acesso em: 30 set. 2014

BELCHIOR. Como nossos pais. Disponível em: <http://www.youtube.com/ watch?v=2qqN4cEpPCw $>$. Acesso em: 30 set. 2014

CAMARGO, R. A. Luz e cena: processos de comunicação co-evolutivos. 2006. 181f. Tese (Doutorado em Comunicação e Semiótica) - Curso de Comunicação e Semiótica, Pontifícia Universidade Católica de São Paulo, São Paulo, 2006.

CARNEIRO, C. Ne me quitte pas. Cena do espetáculo Varekai - Cirque du Soliel's. Disponível em: <https://youtu.be/PVqoQkgLM_E>. Acesso em: 18 nov. 2015.

GOMES, M B. Branco ou Augusto? A Duplicidade em cena: O palhaço em "estado de "transformação". 2012. 142f. Dissertação (Mestrado em Artes) - Curso de Artes, Universidade Federal de Uberlândia, Uberlândia, 2012.

GUARIZO, J. Na vida anterior. Disponível em: <https://www.youtube.com/watch?v=Z4rqtnCpEWM>. Acesso em: 30 set. 2014.

MOURA, L. R. G. A iluminação cênica no trabalho do ator de teatro. 2014. 132f. Dissertação (Mestrado em Artes Cênicas) - Curso de Artes Cênicas, Universidade Federal do Rio Grande do Norte. Natal, 2014.

O PASSARINHO do relógio. Disponível em: <https://www.youtube.com/watch?v=jvVtqvOasLk>. Acesso em: 22 out. 2015.

PEREZ, V. Desenho de iluminação de palco: pesquisa, criação e execução de projetos. 2007. 145 f. Dissertação (Mestrado em Multimeios) - Curso de Artes, Universidade Estadual de Campinas, Campinas, 2007.

Recebido em 26/08/2015 Aprovado em 20/10/2015 Publicado em 21/12/2015 